\title{
Simple Characterization Of Betalain Compound From Red Pitaya (Hylocereus Polyrhizus) Peel Solution
}

\author{
Anni Faridah $^{\# 1}$, Daimon Syukri ${ }^{*}$, Rahmi Holinesti ${ }^{\# 2}$ \\ \# Faculty of Engineering, Padang State University, West Sumatra 25131, Indonesia \\ E-mail: Ifaridah.anni@gmail.com; ${ }^{2}$ holinesti_naldi@yahoo.co.id \\ *Faculty of Agricultural Technology, Andalas University, Padang, West Sumatra, Indonesia \\ E-mail:daimon_syukri@yahoo.co.id
}

\begin{abstract}
The peel of red pitaya (Hylocereus polyrhizus) is often regarded as a waste hence. While the red pitaya peel contain betalain pigment which is useful as a natural colourant for functional food and can be applied to food products. The aim of this study was to simple characterization of betalain compound from red pitaya (Hylocereus polyrhizus) peel. The extraction method employed the use of distilled water, since betalain peel is water soluble. The compound of betalain in the solution was determined by HPLC analysis, spectrophotometrically at $200 \mathrm{~nm}$ to $800 \mathrm{~nm}$ with a UV-Vis spectrometer and Measurement stability, Antioxidant capacity and Antibacterial Activity. Concentration of the sample solution was 7,72 $\mathrm{mg} / 100 \mathrm{~g}$. Absorption peak at a wavelength of $540 \mathrm{~nm}$ obtained from solution of samples showed the presence of betalain compound. The main compound present in a sample suspected of betanin, isobetanin and betanidin that compared to standard. Increasing betalain degradation rates resulting from increasing temperature. Sample solution has antioxidant activity, but weak, and do not to have antimicrobial activity.
\end{abstract}

Keywords - betalain, red pitaya (Hylocereus polyrhizus) peel, antioxidant, antimicrobial.

\section{INTRODUCTION}

Natural colourants from plant sources are receiving growing interest from both food manufacturers and consumers in the continuing replacement of synthetic dyes [1], [2]. Nature produces a variety of compounds adequate for food colouring, such as the water-soluble betalains, anthocyanins, and carminic acid, as well as the oil soluble carotenoids and chlorophylls [3]. However, replacing synthetic dyes with natural colorants offers a challenge because the colour and stability of plant pigments are dependent on several factors, including structure and concentration of the pigment, temperature, $\mathrm{pH}$, light intensity, presence of, metallic ions, enzymes, oxygen, ascorbic acid, sugars and their degradation products [4].

Generally, increasing temperature in food processing will decrease betalain pigment stability. Characterization stable aqueous colorant solution (e.g. juices or solution of fruit or vegetable) is attractive because their GRAS (Generally Recognized As Safe) status makes them easily commercialized. Betacyanins are the group of reddish to violet betalain pigments that are common in many flowers and fruits. Betacyanin can be classified into four kinds: betalain, amaranthin, gomphrenin and bouginvillein. They are water-soluble betalain pigments derived by glycosylation of betanidin, [5], [6]. They have antioxidant, antimicrobial, anti-inflammatory and anticancerous property which can be better studied as the natural source of food colorant [7], [8]. [9] reported that betalain pigments can be applied to food products such as Indonesia cakes, drinks, ice cream, jelly, pudding, jam and lunkhead. It is presumed that betalain pigment concentration in these products is quite low. The low concentration of betalain characteristic that applied in food products is very important to study. The objective of this research is to know the simple characterization (stability, antioxidant and antibacterial activity) of betalain from red pitaya (Hylocereus polyrhizus) peel. Distilled water is used as the extraction medium since betalain is water soluble. The compound of betalain in the solution was determined by using HPLC analysis, spectrophotometrically at $200 \mathrm{~nm}$ to $800 \mathrm{~nm}$ with a UV-Vis spectrometer to measure its stability. Its antioxidant capacity and its antibacterial activity were also measured.

\section{MATERIALS AND METHODS}

\section{A. Material, Solvents and Reagents}

Fruits were obtained from certain sources in Padang, West Sumatra, Indonesia and stored for 5 days. Solvents and 
reagents used were betalain standard (sigma), distilled water, citrate-phosphate, formic acid, acetonitrile, DPPH (2,2-diphenyl-1-picrylhydrazyl), ethanol, acetic acid, and eritrosin (commercial synthetic red dye), bacteria Staphylococcus and Salmonella typhimurium.

\section{B. Sample Preparation}

Red pitaya peel that has been stored for 5 days with the water solvent were extracted using solvent ratio of 4: 1, extraction temperature $36{ }^{\circ} \mathrm{C}$, and the extraction of 9 hours. The solution was filtered and centrifuged solution and then prepared for analysis.

\section{Betalain Determination}

The compound of betalain in the solution was identified by spectrophotometrically at $200 \mathrm{~nm}$ to $800 \mathrm{~nm}$ with a UVVis spectrophotometer. Betasianin analysis was performed by taking samples of $1 \mathrm{ml}$, diluted with citrate-phosphate buffer pH 5 and measured absorbance at $\lambda 537$ and $\lambda 500$. Value absorbance was calculated with $\mathrm{A}=1.095$ ( $\lambda 537$ $\lambda 500)$ [10]. Betalain concentration calculation based on the formula:

$$
\frac{\mathrm{A} \times \mathrm{FP} \times \mathrm{BM} \times 1000}{\varepsilon \times 1}
$$

(A: absorbance; FP: dilution factor; BM: 550g/ mol; $\varepsilon$ : $60000 \mathrm{~L} / \mathrm{mol} \mathrm{cm}, 1$ : cuvette of $1 \mathrm{~cm}$ thick)

\section{HPLC Analyses}

HPLC analyses were performed on HPLC (UFLC Shimadzu HPLC-System). The analytical column Shimpack $250 \times 4 \mathrm{RP}-18(5 \mu \mathrm{m})$ was operated at $30^{\circ} \mathrm{C}$. Solvents were $0.2 \%(\mathrm{v} / \mathrm{v})$ formic acid in water (A) and acetonitrile (B). At a flow rate of $1 \mathrm{~mL} / \mathrm{min}$, simultaneous monitoring was performed at $535 \mathrm{~nm}$

\section{E. Measurement of the Stability}

Measurement of the color intensity of betalain solution was performed on four temperature treatment $(30,50,70$ and $100^{\circ} \mathrm{C}$ ). Each solution was measured with a maximum wavelength double beam spectrophotometer Shimadzu UV1800 with an area measuring wavelengths between 200 $800 \mathrm{~nm}$

\section{F. Determination of Antioxidant Capacities}

The ability to scavenge DPPH free radical was determined based on the method of Brand Williams with minor modification [11]. Briefly, reaction mixtures that containing 20, 40, 60 and $80 \mu \mathrm{L}$ solutions and $2 \mathrm{~mL} 6.25 \times$ 10-5 M DPPH solution were prepared, mixed, and then reacted in the dark for $30 \mathrm{~min}$. A control sample containing the same volume of solvent in place of solution was used to measure the maximum 2,2-diphenyl-1-picrylhydrazyl (DPPH) absorption. The absorbance at $517 \mathrm{~nm}$ was recorded to determine the concentration of the remaining DPPH.

\section{G. Determination of Antibacterial Activities}

The solution was investigated for its antimicrobial activity. Sterile nutrient agar was inoculated with the test organism under sterile condition and then poured into sterile petri dishes. A sterile cork borer was used to remove five plugs from each agar plates to produce $8 \mathrm{~mm}$ diameter wells. Then each disc is dropped by $25 \mu \mathrm{L}, 50 \mu \mathrm{L}, 100 \mu \mathrm{L}, 200 \mu \mathrm{L}, 400$ $\mu \mathrm{L}$ of solution solution and allowed to diffuse at room temperature for 20 minutes and the plates were incubated overnight at $37{ }^{\circ} \mathrm{C}$. Test sample was tested against each organism in duplicate. The calculated of agar diffusion technique was used as zone of inhibition. The recorded diameter of inhibition zones of growth measured in millimetres will be reported [12].

\section{RESULT AND DISCUSSION}

\section{A. Characterization of Betalain with the Spectrophotometer}

The measurement of UV-Vis spectra of the sample solution that obtained from the peak wavelength range of visible light was at $540 \mathrm{~nm}$ wavelength showed in figure 1.
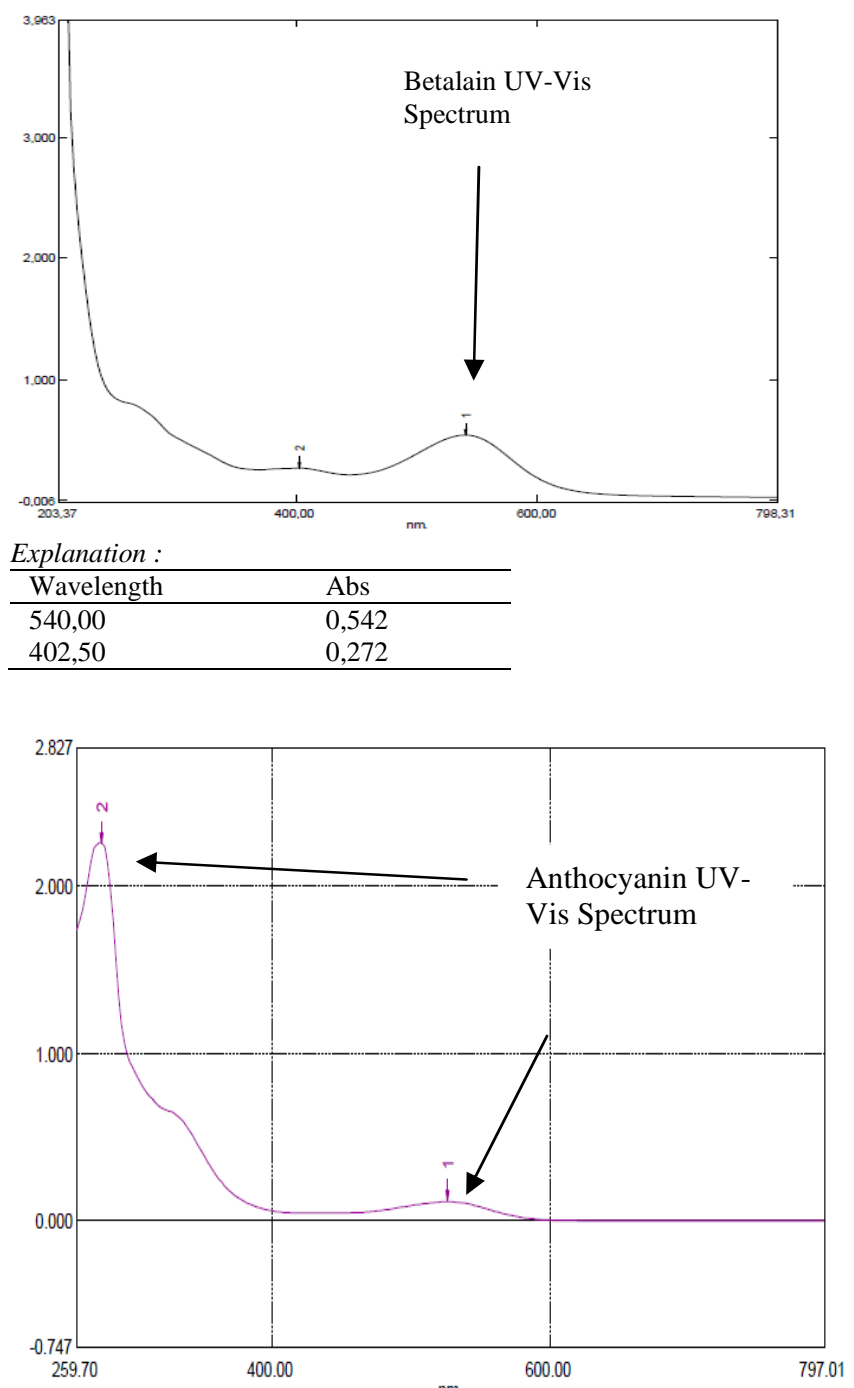

\begin{tabular}{ll}
\hline Explanation : & \\
\hline Wavelength & Abs \\
\hline 526,00 & 0,115 \\
278,00 & 2,221 \\
\hline
\end{tabular}

Fig 1. UV-Vis spectra of the sample solution at a wavelength of $540 \mathrm{~nm}$

Spectrophotometric data from aqueous solution of red pitaya peel recognized by the absorbancy of the sample 
solution, of the data it can be calculated betalain content in the solution. It was found that the level of aqueous solution of red pitaya peel of 7,72 mg / $100 \mathrm{~g}$. Concentration obtained was very small due to the small amount of betalain content in the solution.

The presence of a dominant absorption peak at a wavelength of visible spectra obtained from solutions of samples showed the presence of the compound betalain. This confirm the differences between the betalain compound and antosianin compound. The emergence of a dominant peak indicated that there was a class of compound betalain which was not a group of anthocyanin. One peak that appears was given by the uptake of conjugated double bonds contained in betalain structure, whereas anthocyanin which have a more complex structure in which containing the benzoil and the cinnamoyl skeleton that will give two observations main absorption peak in the wavelength range of UV and visible light. Anthocyanin has two characteristic absorption at the wavelength region, UV (260-280 nm) and visible (490-550 $\mathrm{nm})$.

The spectrum observation of sample solution found an absorption as a shoulder at 310-340 nm, showed the possibility of the compound contained in betalain solution has aslilasi aromatic organic acid or glycosylation with sugar molecules. Betalain existing group consist of several compound that bind to molecules of sugars. Based on the observation of the UV-Vis spectrum of possibilities which was detected only compound total betalain. If the composition of betalain compound in a sample solution has no dominant or relative as much it will be difficult to predict the type of a betalain based on observation of the UV.

For comparison the spectral data which was obtained from spectrophotometer measurement with the data from the literature for the determination of compound in a sample solution showed betalain was not good enough. Then to minimize confusion you should use a standard material, but because of many variaties of betalain compound that exist so little is also likely to be able to get a betalain standards in accordance with the existing betalain compounds in the solution of the sample being tested, based on this is required a more in-depth analysis Reviews such as analysis by HPLC system.

\section{B. Characterization of Betalain by HPLC Analysis}

Based on the results of HPLC analysis, it can be seen betalain separation on HPLC chromatogram obtained from a sample solution compared with standard betalain chromatogram (Figure 2). At the peak of the chromatogram allegedly identified several classes of betalain compound. Compared with standard peak of betalain that the first peak appeared at a retention time of 8,459 minutes, the second peak appeared at 10,707 minutes and the third peak appeared at 11,725 . Each peaks had the same retention time that derived from standard, this indicated that the second chromatogram were betanin, isobetanin and betanidin [13]. Based on the retention time of betalain emergence peak, only a few of betalain compound having different polarity compared to the previous betalain, this may be due to the difference in sugar or acyl bound on betalain aglycone compounds. Analysis of the temperature treatment.

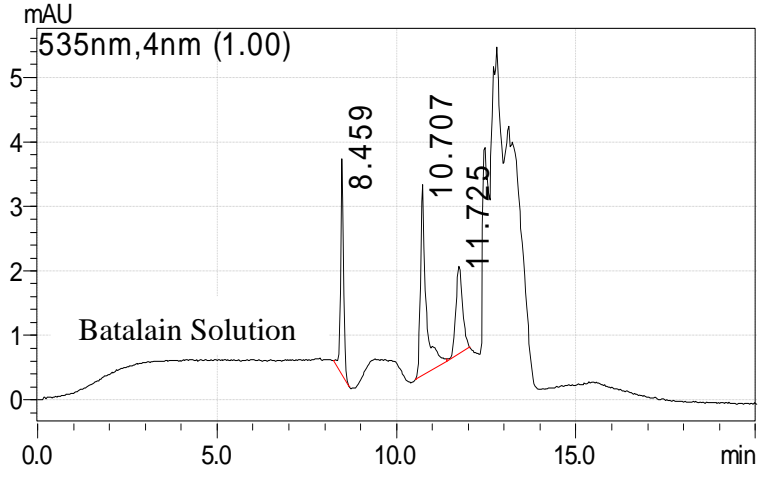

$\mathrm{mAU}$

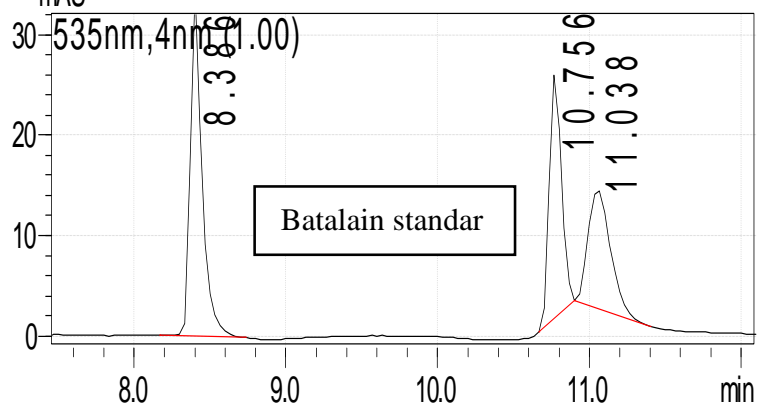

Fig 2. Betalain separation on HPLC chromatogram obtained from a sample solution compared with standard betalain chromatogram

\section{Measurement of the Stability of Betalain Solution from Temperature Treatment}

Red pitaya peel water's solution treated by heat at various of temperature such as 30 (as a control), 50, 70 and $100^{\circ} \mathrm{C}$. Heat treatment carried out for 15 minutes in the oven, a point to see the degradation or damage betalain with the treatment given temperature. Reason takes over the temperature variation to the application as a dye for food and beverage processing, because in general the food and beverage processing using a water system that using the temperature of the boiling point of water is $100^{\circ} \mathrm{C}$ [14]. Observation on the treatment given to the effect of temperature in the solution which has been diluted with a water solvent, where the water was the basis of a solvent commonly used in food processing.

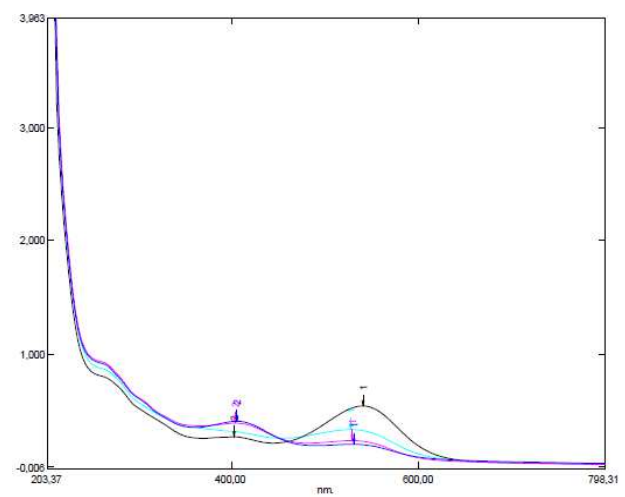

Explanation :

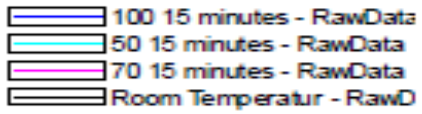

Fig 3. Betalain Solution Stability Influenced by Temperature 
TABLE I

INFLUENCED OF TEMPERATURE TO THE SPECTRUM OF EXISTING BETALAIN COMPOUND

\begin{tabular}{|l|c|c|}
\hline \multirow{2}{*}{ Treatment } & \multicolumn{2}{|c|}{ Wavelength } \\
\cline { 2 - 3 } & 530 & 400 \\
\hline RT & 0,542 & 0,272 \\
\hline 50 & 0,335 & - \\
\hline 70 & 0,238 & 0,392 \\
\hline 100 & 0,205 & 0,409 \\
\hline
\end{tabular}

The treatment temperature in the sample solution can be seen from the data that was attached to the table that the treatment temperature influenced the spectrum of existing betalain compound. From the data it can be observed that the treatment temperature of the sample solution provides observation impairment absorbance of the sample solution was not given temperature treatment. At wavelength of maximum $530 \mathrm{~nm}$ was increased betalain degradation rates resulting from increasing temperature, this was based on the research [15], [16]. [17] reported that betacyanin pigmentation decrease at $40,50,60^{\circ} \mathrm{C}$ but increased at 0,10 , $20^{\circ} \mathrm{C}$. The absorbance at the maximum wavelength of betalain compound in the sample solution decreased by the rise of temperature. This showed the presence of betalaian compound degradation contained in the sample solution. But there were interesting things can be seen from the data of existing spectrum, with decreasing values at a wavelength of maximum absorbance at $\pm 530 \mathrm{~nm}$ betalain, an increase in the value of the absorbance at a wavelength of $400 \mathrm{~nm}$. This showed along with the degradation of betalain form other compound with maximum wavelength of about $\pm 400 \mathrm{~nm}$ which was the region of the yellow color spectrum. This can be examined more deeply by HPLC-MS analysis.

\section{Antioxidant Activity}

The antioxidant activity of the sample solution quantitatively determined by DPPH (1,1-diphenyl-2picrylhydrazyl), betalain in reducing or capturing DPPH radical. These capabilities can be seen from the decrease in the intensity of the purple color of the DPPH solution was added to the sample. Reduced intensity of the color of DPPH solution may indicated that the test material reaction with DPPH radical molecules form the compound 1,1-diphenyl-2pikrilhidrazin yellow. The greater the concentration of the test material, yellow color will be stronger. Reduction of the intensity of the color purple is quantitatively DPPH solution can be calculated from the decrease in the absorbance of the solution. The greater the concentration of the test substance absorbance read smaller, which means that the activity of the test material in capturing greater DPPH radical. The measured absorbance of DPPH absorbance rest that did not react with the test solution.

DPPH free radical scavenging activity of the solution samples can be expressed by parameters EC50 (efective consentration) is the concentration of test compound that led to the capture of the free radicals by $50 \%$. EC50 values determined from the linear regression equation between the concentration of the test material with the free radical scavenging percentage of the average of each concentration.

In particular, the compounds can be said to be a very powerful antioxidant if EC50 values of less than $50 \mathrm{ug} / \mathrm{ml}$, strong for EC50 worth 50-100 ug / $\mathrm{ml}$ and the medium for EC50 worth 151-200 ug / ml (Widyaningsih, 2010). The antioxidant activity of the solution samples, EC50 value was more than $200 \mathrm{ug} / \mathrm{ml}$, this indicates that the sample has a weak antioxidant activity. This might be due to the concentration of active substances in the solution low as solution solvent removal process has not been carried out, because the solutionion was done using water solvent so that the solvent removal process is quite difficult to remove because of the high boiling point of water

\section{E. Antimicrobial Activity}

The result showed that the solution has no significantly comparable antimicrobial activity against the well-known microorganisms. This may relate to the same conditions as the test antioxidant activity where the concentrations of the solution was not high enough because there were many existing water solvent, thus making the bioactivity of the active compounds in the solution was not too optimal. it is very interesting to study further the concentration of the sample solution or by solvent removal process by means of freeze drying.

\section{CONCLUSIONS}

Compounds contained in the solution of red pitaya peel was betalain group confirmed their absorption maximum wavelength of 540 . The solution of red pitaya peel contains the main compound were betanin, isobetanin and betanidin. Stability of solution in red pitaya peel was increasing betalain degradation rates resulting from increasing temperature. The antioxidant activity of solution in red pitaya peel, EC50 value was more than $200 \mathrm{ug} / \mathrm{ml}$, this indicates that the sample has a weak antioxidant activity. And the antimicrobial test, the result showed that the solution has no significantly.

\section{ACKNOWLEDGMENT}

We would like to thank to Indonesia Ministry of Education on research funding 2015.

\section{REFERENCES}

[1] Stintzing FC, and Carle R, "Functional properties of anthocyanins and betalains in plants, food, and in human nutrition," Trends Food Sci Techn, vol. 15, pp. 19-38, 2004.

[2] Francis FJ, "Food colorants: Anthocyanins," Critical Rev Food Sci Nutr, vol. 28, pp. 273-314, 1989.

[3] Henriette MC, and Azeredo, "Betalains: properties, sources, applications, and stability - a review," International J Food Sci Technol, vol. 44, pp. 2365-2376, 2009.

[4] Mazza G, and Miniati E. Introduction, In: Anthocyanins in Fruits, Vegetables, and Grains. Chap 1. Boca Raton, FL: CRC Press; 1993. pp. 1-28.

[5] Strack D, Busch E, and Klein E, "Anthocyanin patterns in European orchids and their taxo nomic and phylogenetic relevance," Phytochemistry, vol. 28, pp. 2127-2139, 1989

[6] Strack D, Vogt T, and Schliemann W, "Recent advances in betalain research," Phytochemistry, vol.62, pp. 247-269, 2003.

[7] Kanner, K., Harel, S., and Granit, R., "Betalains - A new class of dietary cationized antioxidants," Journal of Agricultural and Food Chemistry, vol. 49, pp. 5178-5185, 2001.

[8] Khalida Y, "A comparative study on the extraction of betacyanin in the peel and flesh of dragon fruit," degree of Bachelor, Faculty of Chemical and Natural Resources Engineering Universiti Malasyia Pahang, Malasyia, 2010. 
[9] Faridah A, Holinesti R and Andromeda. (2014) Extraction, characterization, purification, and identification of betalain from red pitaya (Hylocereus polyrhizus) peel. (online)..

[10] Khuluq A D, S B Widjanarko, and Erni Sofia Murtini, "Ekstraksi dan stabilitas betasianin daun darah (alternanthera dentata) (kajian perbandingan pelarut air : etanol dan suhu ekstraksi)," Jurnal Teknologi Pertanian, vol 8 (3), pp. 172-181, 2007.

[11] Brand-Williams W, Cuvelier ME, and Berset C, "Use of a free radical method to evaluate antioxidant activity," Lwt-Food Sci. Technol, vol. 28, pp. 25-30, 1995.

[12] Carson, C.F. and T.V. Riley, "Antimicrobial activity of the major components of the essential oil of Melaleuca alternifolia," $J$. of Applied Bacteriology vol. 78, pp. 264- 269, 1995.

[13] Kavitha Ravichandran, Nay Min Min Thaw Saw, Adel A.A. Mohdaly, Ahmed M.M. Gabr, Anja Kastell, Heidi Riedel, Zhenzhen Cai, Dietrich Knorr, and Iryna Smetanska, "Impact of processing of red beet on betalain content and antioxidant activity," Food Research International," vol. 50, pp. 670-675, 2013.
[14] Adlis Santoni, Djaswir Darwis,dan Sukmaning Syahri,2013, Isolasi Antosianin dari Buah Pucuk Merah (syzygium campanulatum korth.) Serta Pengujian Antioksidan dan Aplikasi sebagai Pewarna Alam, in Prosiding Semirata FMIPA Universitas Lampung.

[15] García Barrera FA, Reynoso CR, Gonzá lez de Mejía E, "Estabilidad de las betalaí nas extraı' das del garambullo Myrtillocactus geometrizans)," Food Sci Technol Int, vol 4, pp. 115-120, 1998.

[16] Herbach, K. M., Stintzing, F. C., \& Carle, R. (2004a). "Thermal degradation of betacyanins in juices from purple pitaya (Hylocereus polyrhizus [Weber] Britton \& Rose) monitored by high-performance liquid chromatography-tandem mass spectrometric analyses," European Food Research and Technology, vol. 219, pp. 377-385, 2014.

[17] Reshmi S.K, K. M. Aravindhan and P. Suganya Devi, "The effect of light, temperature, $\mathrm{pH}$ on stability of betacyanin pigments in basella alba fruit," Asian Journal of Pharmaceutical and Clinical Research," vol. 5, pp. 107-110, 2012. 